\title{
DIMENSIONADO DE LA DEMANDA DE VIVIENDAS EN LA COMUNIDAD AUTÓNOMA DE ANDALUCÍA
}

Antonio MARTÍN GARCÍA*

\section{INTRODUCCIÓN}

Dos son, principalmente, los problemas con los que nos encontramos a la hora de realizar un dimensionado de la demanda de viviendas: la inadecuación de la estadística oficial existente y la ausencia de una metodología solvente, contrastada y fiable, para operar en las distintas escalas territoriales.

Estas circunstancias estructurales adversas nos obligan, máxime cuando pretendemos intervenir en un espacio tan amplio como es la Comunidad Autónoma de Andalucía, no sólo a razonar, fundamentar la selección de las variables del método, sino a establecer hipótesis equilibradas de su comportamiento futuro, además de recordar que estamos hablando de grandes números, necesarios de acotar en una fase posterior de la investigación, cuando proceda abordar la territorialización de la demanda.

La falta de bondad de las fuentes oficiales de estudio, -básicamente censales-, para elaborar aproximaciones al dimensionado de la demanda potencial de viviendas, se descubre incapaz de aportar luz para valorar las componentes no sólo cualitativas, también de las cuantitativas, que concluyan en el ajuste de la demanda real. Nos estamos refiriendo a la ausencia de información estadística del tipo: familias residentes, número de viviendas no reparables, datos fiables sobre la infravivienda...

De ahí que, el condicionamiento de las fuentes invite al abandono de procesos metodológicos que consideran, por ejemplo, variables tales como migraciones interiores o externas, aplicaciones de proyecciones demográficas a las pirámides de población calculada..., dado que nos obligaría a recurrir a simulaciones o hipótesis matemáticas, al uso de construcciones de laboratorio que se intentan

\footnotetext{
* Doctor en Geografía y Licenciado en Derecho. Gerencia Municipal de Urbanismo. Sevilla.
} 
salvar con el paraguas de la cientificidad y obviando la realidad estadística a la que, por otra parte, los modelos que emplean tales procedimientos tienen, necesariamente, que atribuirle gran confianza y escaso margen de error; todo ello para esconder una elevada confusión conceptual, justificar una abigarrada elaboración artificial y ausencia de estructura clara, diferencial y fundada.

También los modelos de ajuste de la demanda, en base a Encuestas de Hogares, se encuentran con la limitación de la estadística oficial, de la que se alimenta para sus cálculos, al tener que considerar el volumen de la demanda por constitución de nuevas unidades familiares (vía nupcialidad, emancipación...), o debido a la movilidad residencial, (cambio de residencia a escala infra o supra regional, localización de la $2^{\text {a }}$ vivienda...). Pero la concrección de la demanda en base a estos modelos resulta, además, costosa y parcial, -pues obligan a extender sus resultados a universos no suficientemente estudiados-, lo cual exige una importante deseconomía de tiempo y dinero, a la vez que a generosas muestras de fe.

\section{METODOLOGÍA}

Hechos los anteriores comentarios críticos, de carácter general, a las fuentes y al "alma" de los modelos de ellas dependientes, (fórmulas unicuacionales, que si bien son tan numerosas como autores existen, sólo se diferencian por pequeños matices o variables), la situación nos obliga a producir un modelo que supere, siquiera parcialmente, los efectos insatisfactorios que se desprenden de semejantes metodologías.

El método empleado, que expondremos a continuación, goza, a nuestro juicio, de claridad estructural y solvencia operativa, (lo cual permite individualizar y corregir con facilidad los desajustes o modificar, en cualquier dirección, las hipótesis iniciales sin que el sistema se destruya), de un carácter acumulativo y diferencial que comienza con el ajuste de la demanda potencial y real actual, continúa con la previsión en un futuro próximo, -1995 y 2000-, de ambos conceptos y, por último, ofrece la posibilidad de concretar las necesidades de suelo residencial para atender la cobertura de demanda de viviendas.

Entendemos que la demanda potencial actual se compone a partir del número de familias residentes, (considerando por residentes la población de hecho), que comparte viviendas, y de aquellas viviendas que, por estar en mal estado, no son reparables '. Si bien el número de viviendas ocupadas por familias residentes

1. Las viviendas no reparables es un concepto más amplio que el de viviendas en ruínas, administrativamente declaradas, esto es, englobaría viviendas en ruína oficial y física. La experiencia en trabajos anteriores, -nos estamos refiriendo a estudios realizados en apoyo del planeamiento urbanístico 
requeriría que su instrumento de cálculo, -el índice de hacinamiento, (familiàs) vivienda)-, se obtuviera por muestreo, sistema del todo punto inabordable en estos momentos, su ajuste a través de considerar sólo la población de hecho y las viviendas cuantificadas como principales por el Censo de Población y Viviendas en 1991, permite minorar la posible desviación que pudiera obtenerse respecto al método apuntado.

Obtenida de esta forma la demanda potencial, a nivel de Andalucía, hemos concluido en la cuantificación de la demanda real valorando, sólo, las siguientes situaciones patológicas: demanda insolvente; población dependiente que convive con familiares; familias que habitan la vivienda en régimen de alquiler, con cuotas elevadas para sus ingresos y, por último, constitución de nuevas familias.

Si nos detuviéramos aquí, tendríamos la situación de la demanda actual. No obstante, es deseable realizar una previsión, y así lo hicimos, de la demanda potencial a partir de unas hipótesis de evolución del número de familias residentes y del tamaño de la composición familiar, (personas/familia), futura, eso es, años 1995 y 2000 . Pues, como bien sostienen, "la demanda de viviendas principales a largo plazo viene explicada por la necesidad existente y por la capacidad de pago de las familias, estando la necesidad de viviendas ligadas al proceso de formación de nuevos hogares. En este sentido se están produciendo en España dos evoluciones de signo contrario... la reducción abrupta de la natalidad... y el aumento de los hogares es ahora muy superior al aumento de la población, por razones estrictamente demográficas" 2 .

Junto a la previsión de la demanda potencial estableceremos la de la demanda real a partir del comportamiento esperado de los factores de carácter patológico, enunciados anteriormente. La obtención de la demanda real para el umbral temporal de las dos próximos quinquenios es básico para establecer las necesidades

en pueblos como Constantina, Peñaflor, Brenes y el Casco Antiguo de Sevilla-, y dado que no existe estadística municipal y/o regional al respecto, nos recomienda una valoración, de este tipo de inmuebles, entre el 4 y $6 \%$ del parque de viviendas principales existentes. Y esos van a ser los valores de las hipótesis mínimas y máximas manejados para el ajuste de la demanda potencial.

Para fortalecer los guarismo anteriores baste lo siguiente: "una construcción, o parte de ella, se encuentra en estado ruinoso cuando el coste de la reparación, hasta asegurar las condiciones de seguridad y salubridad, sea superior al 50\% del valor de la construcción", (art. 15 del Anteproyecto de Ley de Medidas de Protección de la Legalidad Urbanística. Junta de Andalucía, enero, 1986). Por otra parte, también en el mismo año, el consejero de Política Territorial sentenciaba que, "una tercera parte de los edificios destinados a vivienda poseen defectos en su estado constructivo y que, en la década de los setenta, la degradación progresiva del parque de viviendas, ha colaborado a la pérdida de unos 200.000 edificios residenciales en Andalucía". (I Jornadas de FADECO sobre Política de Vivienda en Andalucía).

2. "Una aproximación a las necesidades de vivienda en España: Proyecciones 1990-2000". RODRÍGUEZ, J.; CURBELO, J.L.; MARTÍN, V. Revista Española de Financiación de la Vivienda ${ }^{\circ}$ 14-15, Marzo, 1991, Banco Hipotecario de España, Madrid. 
de suelo residencial; si bien, el dimensionado de éste último factor nos obliga a reflexionar sobre el fenómeno de las viviendas no ocupadas permanentemente, (ejercicio que se nos escapa en estos momentos, dado que desconocemos, por ejemplo, el volumen de la vivienda de ocupación estacional en ejercicios precedentes y, también, el número de viviendas vacías absoletas, ya sea por motivos físicos, funcionales o locacionales, entre otros muchos datos sobre los modos de ocupación no permanente y de tipos de viviendas vacías). De la evaluación que hagamos en un futuro próximo, a partir de su cuantificación presente, va a depender la capacidad del parque existente, hoy día, para absorber parte de la demanda o, por el contrario, para incrementarla.

\section{DEMANDA POTENCIAL DE VIVIENDAS EN ANDALUCÍA. INDICACIONES TERRITORIALES}

De acuerdo con la metodología expuesta, la consideración que se haga de Ias variables de la demanda potencial, muy dependiente del tratamiento de los datos censales, va a determinar no sólo el volumen de las necesidades de vivienda, sino su localización territorial.

a) Número de familias residentes. Si nos limitáramos al dato que establece el Censo de Viviendas de 1991, estaríamos elaborando una información grosera y poco fiable para determinar una demanda potencial toda vez que, en defecto de un concepto unitario de familia residente, el I.N.E. lo calcula en base a la población de derecho, (presentes + ausentes). Nosotros partimos de la población de hecho, (presentes + transeúntes): 6.963 .116 habitantes, y el índice de composición familiar medio en Andalucía, (3’525 personas/familia), en 1991. El resulta'do fue "descubrir" 35.443 familias más que las cuantificadas por el Censo, a nivel regional. Pero, además, este proceso, pulido y trabajado, condicionó el resultado de la siguiente variable.

b) Número de viviendas ocupadas por familias residentes. Si no hubiéramos perfeccionado la información anterior, el índice de hacinamiento no habría alcanzado el óptimo equilibrio de la unidad, en concreto, sólo sería de 0’99 familias/ vivienda y, en consecuencia, nos encontraríamos con un gran sarcasmo: en Andalucía no hay demanda potencial de viviendas. Sin embargo, la concrección deI número de familias residentes por el procedimiento descrito hace que el índice de hacinamiento, en la Comunidad Autónoma, se sitúe en 1'01 y, en consecuencia, la demanda potencial, por ambas variables, alcanza las 19.796 viviendas ${ }^{3}$.

3. A nivel de España, las necesidades de vivienda a construir cada año se cifran entre 250-275.000 
No obstante, cuando el tratamiento de las anteriores variables se realiza con los datos referidos a nivel provincial, el ajuste de la demanda se corrige, al alza, y se perfecciona su dimensionado por la mayor concrección espacial-estadística. De ahí que el sumatorio de las demandas potenciales provinciales de vivienda alcance hasta las 28.849 unidades, esto es, un $45^{\prime} 7 \%$ más que la detectada a escala regional. Pero si seguimos bajando en los ámbitos de análisis, el procedimiento de cálculo sigue deparándonos mayor aproximación a la realidad social. Pues, en las provincias donde no se detectó demanda, (Figura $\mathrm{n}^{\mathrm{0}} 1$ ), afloran necesidades de vivienda a nivel municipal, como es el caso de Córdoba, (Figura $\mathrm{n}^{\circ} 2$ ), $\mathrm{y}$, en aquéllas en las que sí se descubrió, la prospección a esta escala arroja un volumen de demanda superior, como ocurre en la provincia de Huelva, (Figura $n^{2}$ 3) $y$, todo ello, a pesar de utilizarse la composición familiar, personas/ familia, media provincial y no, como sería lo adecuado, la existente en cada municipio. De nuevo tropezamos con los límites de la estadística disponible.

c) Número de viviendas en mal restado, no reparables*. Aquí, como ya hemos adelantado, ante la ausencia de series estadísticas, nos conducimos por hipótesis basadas en la experiencia acumulada en este tipo de estudios. Y tal experiencia nos recomienda situarnos en dos supuestos de cuantificación de las viviendas en mal estado, no reparables, dentro de las residencias definidas como principales por el Censo: una hipótesis mínima, que considera su dimensión en un $4 \%$ del parque de viviendas permanentes y, una hipótesis máxima, que lo extiende hasta el 6\%. Dentro de esta banda entendemos se mueve el fenómeno de la vivienda en mal estado, no reparable, que, por otra parte, suele encontrarse muy concentrada en los diferentes núcleos urbanos.

Dependiendo de que seleccionemos uno u otro guarismo relativo de valoración, del anterior tipo de viviendas, tendremos un resultado concreto de demanda potencial que, en cualquier caso, desprende valores absolutos situados entre:

1ª 98.018 viviendas, (con la hipótesis del 4\% de viviendas en mal estado, más el déficit por índice de hacinamiento sobre familias residentes), y/o

unidades. Véase el resumen de las Jornadas Internacionales sobre "El futuro de la Vivienda en el marco de la C.E.E.”, dentro del Salón de la Construcción CONSTRMAT 87, Barcelona.

Por su parte, (I.N.E. 1990; RODRÍGUEZ, CORBELO y MARTÍN, 1991) cifran las necesidades de vivienda en un déficit de $700.000 \mathrm{y}$, aproximadamente, 130.000 anuales, derivadas de la formación de nuevos hogares durante el período 1991-2000.

* Que englobaría también a la infravivienda, esto es: chabolas, cuevas, viviendas rurales sin las condiciones de habitabilidad necesaria y aquellas residencias localizadas en barriadas urbanas deprimidas, en las que la vivienda no cuenta con el equipamiento social necesario. 
$2^{\text {a }} 137.129$ viviendas, (si modificamos el guarismo anterior y lo elevamos hasta el $6 \%$, dejando estabilizadas el resto de variables).

\section{DEMANDA REAL DE VIVIENDAS EN ANDALUCÍA}

Aunque no se dispone de estudios solventes y/o publicados sobre los orígenes de la demanda potencial de viviendas en Andalucía ${ }^{4}$, todo parece apuntar a que no se debe tanto a una escasez de la oferta como a un desajuste entre ofertademanda, teniendo en cuenta que la capacidad de acogida residencial no se limita, teóricamente, a las viviendas de ocupación permanente y que la consideración, siquiera parcial, de las viviendas de ocupación temporal, (secundarias, según el Censo), sería suficiente para cubrir, con creces, Ia demanda potencial expresada. No obstante, la vivienda secundaria es un alojamiento que tiene un uso y/o funcionalidad que la hacen, en realidad, inviable para cubrir la demanda potencial desatendida aunque, a su vez, no deja de constituir, junto con la vivienda desocupada, un stock residencial del que es difícil saber su comportamiento futuro.

Partiendo de la demanda potencial reseñada, para la concrección de la demanda real sólo vamos a considerar, para este artículo, cuatro de las circunstancias patológicas que, por otra parte, han emergido en otros estudios ${ }^{5}$ como las de mayor incidencia, a saber: demanda potencial insolvente; demanda real por vivir en régimen de alquiler con cuotas elevadas, en relación con los ingresos familiares; demanda real por constitución de nuevas familias y, por último peso relativo de las personas, (ancianos preferentemente), que conviven con familiares.

De las cuatro situaciones descritas, la mitad de ellas actúan de restricción de la demanda potencial, (insolvencia económica y personas que conviven con otros familiares) y, las dos restantes, (familias que habitan inmuebles en alquiler con precios abusivos para sus ingresos y la constitución de nuevas familias), de sumatorio de aquélla.

Para el dimensionado de la demanda potencial insolvente hemos tenido en cuenta esta reflexión realizada para el año 1990, "pese a este mayor ritmo de crecimiento, -durante los tres últimos ejercicios de 1987, I988 y 1989-, si analizamos la evolución del P.I.B. en términos per capita, Andalucía sigue estando a

4. Como sí ocurre para la Comunidad de Madrid, por ejemplo. Rev. "Alfoz", n 19.

5. "Población y Vivienda en el Casco Antiguo de Sevilla, 1980-1988. MARTÍN GARCÍA, A. Rev. Aparejadores, n³0. Sevilla, 1989. 
la cola de las Comunidades Autónomas, sólo superada por Extremadura. El P.I.B por habitante (851.499 Pts.) sólo representa el 72’5\% de la media naciona (1.174.207 Pts.)..., el mayor dinamismo económico de Andalucía ha venid، acompañado de un crecimiento de la población superior al medio nacional, por ls que en términos per capita, la posición relativa de la región sólo experimenta el los últimos años una muy pequeña mejoría" ${ }^{6}$. Este escenario nos ratifica en li verosimilitud, -pues, además, en $1990^{7}$ los ingresos salariales medios en $1_{i}$ Comunidad de Andalucía fueron de 130.187 Pts./mes, esto es, 2'6 veces el Sala rio Mínimo lnterprofesional (S.M.l.) en este ejercicio-, de la siguiente hipótesis del 50 al 60\% de la demanda potencial de viviendas es insolvente, desde el punt de vista económico, para acceder a una vivienda en propiedad, dado que su ingresos familiares/mes no supera, en 1992, las 2'0 veces el S.M.l., cifrado el $52.280 \mathrm{Pts} . / \mathrm{mes}$ en ese último año. $\mathrm{Y}$, desde luego, con tal nivel de ingreso: resulta imposible dedicar a financiación de la vivienda no ya un $30 \%$, ni incluss el $25 \%$, de su total.

Pero en la configuración de una demanda mayoritariamente insolvente est: influyendo no sólo el nivel "per capita" de las familias carentes de vivienda, sinc también la desproporción económica de la oferta inmobiliaria dominante. E desajuste, el divorcio O/D se ha producido por dos causas:

$1^{\text {a }}$ la oferta residencial de nueva planta estuvo dominada, en una relación 2 : 1, por el régimen constructivo de iniciativa y promoción libre, en relación a li V.P.O., durante el período 1987-1991 ${ }^{8}$.

$2^{\text {a }}$ Consecuencia del punto anterior, los precios inmobiliarios se dispararon er el mismo período, (Cuadro $n^{o} 1$ ), coincidiendo con una menor producción de li vivienda oficial protegida, ya sean de iniciativa pública o privada.

6. Informe Económico-Financiero de Andalucía, 1990. ESECA.

7. Encuesta de Salarios I.N.E. Madrid, 1990.

8. Según la Dirección General de Arquitectura y Vivienda. Consejería de Obras Públicas y Trans porte. Junta de Andalucía. 


\section{CUADRO 1}

Precios Inmobiliarios (Pts./m²)
en Andalucía, 1987-1991

Ciudad

$\triangle \% 87-91$

JAÉN

205

CÁDIZ

258

CÓRDOBA*

GRANADA

230

HUELVA

216

ALMERÍA

209

MÁLAGA

182

SEVILLA

268

* Sólo se dispone de datos de los ejercicios 90 y 91. Fte. TINSA e Informe de la Sociedad de Tasación, S.A.

Tanto los datos recogidos en el cuadro, como el tratamiento comparado de la variación de los valores medios de tasación de las viviendas nuevas en el período 1987-1992 en Andalucía, con los registrados en España, media nacional, (+12’02 $y+11$ ' 43 , respectivamente) ${ }^{9}$, hacen imposible ratificar el que, "los precios de las viviendas sean en Andalucía inferiores a los del conjunto nacional y la expansión experimentada en los precios ha sido, salvo excepciones, algo menos virulenta que en el resto del país" ${ }^{10}$.

Dada esta situación económica de la demanda, y sin detrimento de que en otra ocasión hagamos una imbricación analítica de los postulados del R.D. 1932/ 1991, de 20 de Diciembre, sobre medidas de financiación de actuaciones protegibles en materia de vivienda del Plan 1992-1995, en Andalucía la única oferta inmobiliaria con posibilidad de éxito, social y de mercado, (entendiendo éste como equilibrio oferta-demanda), es la del régimen de protección especial, (arts. 2.a), 5 y 6 del citado cuerpo legal) y financiación del mismo tipo. Por

9. “La estructura territorial de los precios de la vivienda en España: 1987-1992”. San Martín, I, Rev. Española de Financiación de la Vivienda, n² 22. Marzo, 1993. Banco Hipotecario de España. Madrid.

10. "Andalucía: construcción de viviendas. Una aproximación". RODRÍGUEZ, J. Boletín Económico de Andalucía, nº 12, Año, 1993, pp. 83-93. 
exclusión, la producción de viviendas de protección general, hasta 5'5 veces e S.M.I., de realizarse ampliamente, están destinadas a engrosar, en su mayor parte el parque de viviendas vacías, ser objeto de ocupaciones de hecho, inoficiosas $\mathrm{y} / \mathrm{c}$ ilegales e, incluso, instrumentos de transacciones fraudulentas.

Pero acometer una producción inmobiliaria mayoritaria del modelo V.P.O., régi men especial, requiere, básicamente, disponer de suelo público suficiente obtenids con el menor coste, esto es, vía gestión del planeamiento y aplicando, en toda si extensión, los instrumentos legales disponibles en el R.D.L. 1/91, para incrementa los Patrimonios Municipales de Suelo. Por ello, tanto el Plan Nacional como e Andaluz de Vivienda 92-92 descansan en ese axioma. No en vano se ha sostenidk que, "la cesión de suelo público para hacer viable la construcción de vivienda dt precio tasado y la especial sensibilidad con las que los planes urbanísticos deber tratar el problema de la carestía de la vivienda, son partes integrantes de la nuevi cultura que debe calar en todos los niveles de la Administración" "1. Junto a l: disposición de suelo público, los Planes de Vivienda Andaluz y Nacional vigente: sufren otra dependencia no resuelta y asfixiante: carencia de financiación, ya se: pública, mixta o privada, para acometer la producción de viviendas de régimer especial, las destinadas, precisamente, a cubrir el grueso de la demanda social.

$\mathrm{El}$ otro factor que no puede ser considerado, salvo en una posición de resta, er términos de demanda real, es el nivel de personas que, en cualquier situación socia general, van a convivir con otros familiares compartiendo la vivienda, (ancianos población física y socialmente dependiente...). Según la última encuesta realizad: por el Ministerio de Asuntos Sociales, en 1991, "el 15\% de los mayores de 65 años vive en el domicilio de sus familiares". Por su parte, el Instituto Nacional de Estadís. tica evalúa la escala de emancipación de los jóvenes en su evolución reciente con los siguiente parámetros: el 22’7\% de las personas entre 15 y 19 años vivía en situaciór de autonomía plena en 1984. Cuatro años después, en 1988, el porcentaje habíc bajado al 18'1\%. Por último, la primera Encuesta Sociodemográfica, elaborada pos el I.N.E. y presentada en el mes de Abril de 1993, deduce que el 15'7\% de los hogares españoles están compuestos por la unidad familiar nuclear y otros miem. bros". De ahí que el peso relativo de ese colectivo, (el que comparte vivienda), lc establezcamos en el 15\% de la demanda potencial.

Por ello, hasta ahora, la demanda potencial habría que deflactarla en unc banda que oscila entre el 65 y $75 \%$. Por contra, veámos cual es la base de st incremento, una vez analizada la valoración de las variables expansionistas de le demanda real sobre la potencial. 
En primer lugar, la constitución de nuevas familias la haremos coincidir con la tasa de nupcialidad media de Andalucía, 6'18\% en $1991^{12}$, la cual da lugar a un número de núcleos familiares de 42.889 unidades, esto es, entre un 32 y un $45 \%$ aproximadamente, sobre la demanda potencial. Una vez más, la miseria de la estadística oficial nos conduce a simplificar el ajuste y despreciar la cuantificación, al parecer aún no muy relevante, de los nuevos modelos de unidad familiar y/o uniones de hecho, necesitados, igualmente, de una vivienda. No obstante, este fenómeno social no podrá dejar de ser obviado, durante mucho tiempo, a la hora de dimensionar la demanda residencial de la población.

Para la acotación de la demanda real, que deberá incrementar a la potencial, debido a las familias que ocupan una vivienda en alquiler, con alta renta mensual $y$, por tal motivo, con tendencia a adquirir una vivienda en propiedad, nos hemos apoyado para establecer nuestra hipótesis en la información facilitada por un estudio reciente sobre el alquiler en España ${ }^{13}$. Este trabajo recoge los últimos datos elaborados por el MOPU, (Octubre 1989-Febrero 1990), basados en la Encuesta de Alquileres incluida en la Encuesta de Población Activa que elabora el I.N.E., sobre una muestra de un tercio de la anterior.

La fuente citada establece una media nacional de 35 viviendas de alquiler por 1.000 habitantes que, para el caso de Andalucía, disminuye hasta el guarismo 28. Pero quizás aún más riguroso sea el dato del MOPU que cuantifica la vivienda en alquiler en el 22'3\% del parque, (incluyendo las viviendas principales y secundarias) $y$, donde el $7 \%$ del último valor relativo, soportaba una renta media, en 1989 , en tomo a las 20.000 Pts./mes. A efectos de este estudio, vamos a actualizar los anteriores datos para 1991, a expensas de lo que resulte para cuando se tenga la información estadística al ejercicio presente, en los siguientes valores: un $20 \%$ de viviendas en alquiler y, de ellas, un $10 \%$ soporta rentas superiores a las 30.000 Pts./mes.

Según el último estudio del que tenemos referencia ${ }^{14}$, la situación en España del alquiler residencial, desprende la siguiente radiografía: "el precio medio del alquiler a nivel nacional es de 67.000 Pts, lo que constituye casi la mitad de las 140.000 Pts. de salario medio,... estos datos revelan la carestía y escasez del mercado de viviendas de alquiler en España, (un 18\%, frente al $61 \%$ de Alemania o el 37\% de Francia)". Como ejemplo de ciudad andaluza, la fuente anterior sitúa a Sevilla en la séptima urbe de Europa donde la oferta de viviendas en alquiler tiene el precio más elevado.

12. Anuario Estadístico de Andalucía, 1992. Instituto de Estádística de Andalucía. Sevilla, 1993.

13. La vivienda de alquiler en España: Análisis de la situación actual y propuesta para una reforma. Instituto Sindical de Estudios. Madrid, 1991.

14. Véase "El País", de 4 de Abril de 1992. 
Con la hipótesis defendida, tendríamos un parque de 473.298 viviendas en alquiler en Andalucía; de las cuales, un $10 \%$, en concreto 47.330, están gravadas con rentas superiores a las $30.000 \mathrm{Pts} . / \mathrm{mes}$, cantidad suficiente para que sus inquilinos se planteen acceder a una vivienda en propiedad siempre que su financiación no supere, de forma notable, la última cifra reseñada. Por ello, entendemos que el citado volumen de 47.330 unidades, entre un 35 y un $45 \%$ de la demanda potencial detectada, puede ser configurada como demanda real, adicional, a la primera.

Por todo lo expuesto, consideramos ajustado y, sobre todo razonado, el incrementar la demanda potencial inicial de vivienda entre un 2 y un $18 \%$, con lo cual estaríamos en los siguientes valores absolutos de demanda real para 1991.

La hipótesis reducida de demanda potencial, -las 98.018 viviendas-, alcanzarían 102.919 ó 112.721 unidades; en cambio, la hipótesis ampliada, -las 137.129 viviendas- se extenderían hasta una demanda real de 139.872 ó 161.812 alojamientos.

\section{PREVISIÓN DE LAS DEMANDAS FUTURAS DE VIVIENDA EN ANDALUCÍA}

Acotada la demanda potencial y real de vivienda en Andalucía en la actualidad, 1991, entendemos llegado el momento de establecer una prognosis sobre su comportamiento futuro en los próximos años, tras establecer dos cortes cronológicos concretos: 1995 y 2000.

La previsión de la demanda potencial, calculada para 1991, sólo va a ser corregida a partir de la modificación del número de familias residentes, probables, en los umbrales temporales citados. Esto es, la cuantificación de la variable número de viviendas no reparables, vamos a considerarla estabilizada en los valores de partida, 4 y $6 \%$ respectivamente.

Este proceso nos conduce a prever, en primer lugar, la tasa de crecimiento medio de la población andaluza en los dos próximos quinquenios y, en segundo lugar, la evolución del tamaño de la composición familiar, (persona/familia).

Lo anterior exige conocer cual ha sido la tasa de crecimiento medio de la población, de hecho, en Andalucía, al menos en los últimos veinte años, a saber: 


\section{CUADRO II \\ Tasa de Crecimiento Medio Anual (\%) en Andalucía}

(1970-1991)

\begin{tabular}{|c|c|}
\hline 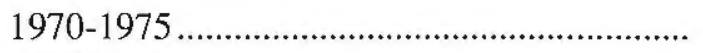 & $+0,53$ \\
\hline $1975-1981$ & $+0 ’ 93$ \\
\hline 1981-1986 & $+1 ’ 30$ \\
\hline 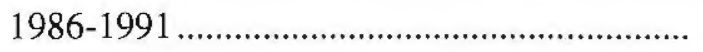 & $+0^{\prime} 25$ \\
\hline
\end{tabular}

Fte. Anuario Estadístico de Andalucía y Censos de Población, e.p.

De los datos demográficos del cuadro cabe concluir un comportamiento estable de la población en el decenio 1975-1986 y una notable falla, retroceso del crecimiento, en el último período censal, lo cual invita a interrogarse sobre la extensión futura del valor de la tasa en el tramo 1986-1991. De ahí que concluyamos, como más verosimil, un índice de crecimiento anual acumulado en torno al $0 ` 4 \%$, de aquí a final de siglo.

Asímismo, la metodología exige cuantificar la otra variable demográfica: composición familiar futura. la evolución reciente de este coeficiente ha ido en descenso, pues de 3’753 personas/familia en 1981, diez años más tarde retrocede hasta las 3'525 ya comentadas, dentro de una dinámica general de disminución no notable, pero progresiva. Por ello, hemos creído realista situarnos en una previsión de la tasa para 1995 de 3'45 personas/familia y de 3'3, hacia el final de siglo.

En base a estas hipótesis, la previsión de la demanda potencial, obviando la cuantificación de las viviendas no reparables, así como la nueva oferta inmobiliaria que se produzca en los próximos años, sería de:

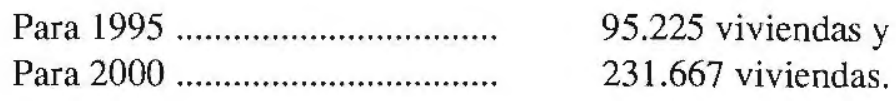

El ajuste de la demanda real futura se concluye aplicándole a las cifras anteriores los guarismos extraídos para su cálculo en 1991, estabilizados en sus valores relativos, (incremento de la demanda potencial entre un 2 y un 18\%), y teniendo como resultados absolutos unas cifras que oscilarán entre: 
Por último, reiterar que a esas cifras habría que añadirles los valores quє resulten de la aplicación del 4 ó 6\%, como parque de viviendas no reparables sobre el total de las consideradas como principales por el Censo y, por otra parte. ir restándoles la nueva oferta de viviendas, de ocupación permanente, que vayan siendo puestas en el mercado inmobiliario y computadas como de uso efectivo ${ }^{15}$. Así como la posible incorporación al uso de parte, al menos, del enorme parque de viviendas vacías, parcial o totalmente que, según el Censo de 1991, alcanza a las 781.060 unidades, en la Comunidad Autónoma, esto es, el $27^{\prime} 62 \%$ del total del parque residencial. Con sólo la puesta en uso de las viviendas íntegramente vacías, 370.131 unidades, sería suficiente para cubrir el déficit, actual y acumulado, hasta el año 2000. Con este escenario, junto a una interpretación avanzada y solidaria de los artículos 33.3, 47 y 128.2 de la Constitución, y otros cuerpos legales, resulta razonable, al menos, reiterar lo propuesto en otro trabajo publicado recientemente, ${ }^{16}$ "la necesidad de dictar Ley sobre Ocupación de Viviendas o crear un impuesto, progresivo, sobre las viviendas desocupadas".

Con los datos previsibles de las distintas demandas, potencial y real, se está en condiciones de dimensionar las necesidades de suelo residencial en Andalucía, si bien ese ajuste requiere un estudio sobre la capacidad del parque actual, y de su comportamiento futuro, de viviendas vacías y de ocupación temporal con capacidad para absorber parte de la demanda o, por el contrario, para incrementarla.

El interés de saber la demanda de suelo residencial,y su localización, descansa en:

- Conocer la capacidad del parque público de suelo, ya sea en manos de los ayuntamientos o de la Empresa Pública de Suelo de Andalucía, EPSA, para atender las necesidades de vivienda.

- Establecer estrategias, desde la planificación pública, para ordenar el mercado inmobiliario y

- Deducir la solvencia existente para cumplir los Planes, Andaluz y Nacional, de Viviendas para el cuatrienio 1992-1995.

Todos esos temas, junto con el análisis del mercado hipotecario y financiero del sector residencial, merecen la reflexión más amplia en otro estudio.

15. En este sentido señalar tan solo que la producción de V.P.O. terminadas, entre promoción pública y protegida, se situó en 15.743 viviendas en 1990 y 9.807 en 1991, a nivel de Andalucía, según fuentes del I.N.E., datos provisionales; durante los primeros once meses de 1992, período de aplicación del Plan Andaluz de Viviendas con datos estadísticos, la producción inmobiliaria protegida alcanzó las 20.609 unidades.

16. "Necesidades de Viviendas y Suelo Residencial en la Ciudad de Sevilla". MARTÍN GARCÍA, A. Rev. CATASTRO, $n^{\circ}$ 18, pp. 78-87. Subdirección General de Estudios y Estadística. $M^{ }$de Economía y Hacienda. Madrid. 


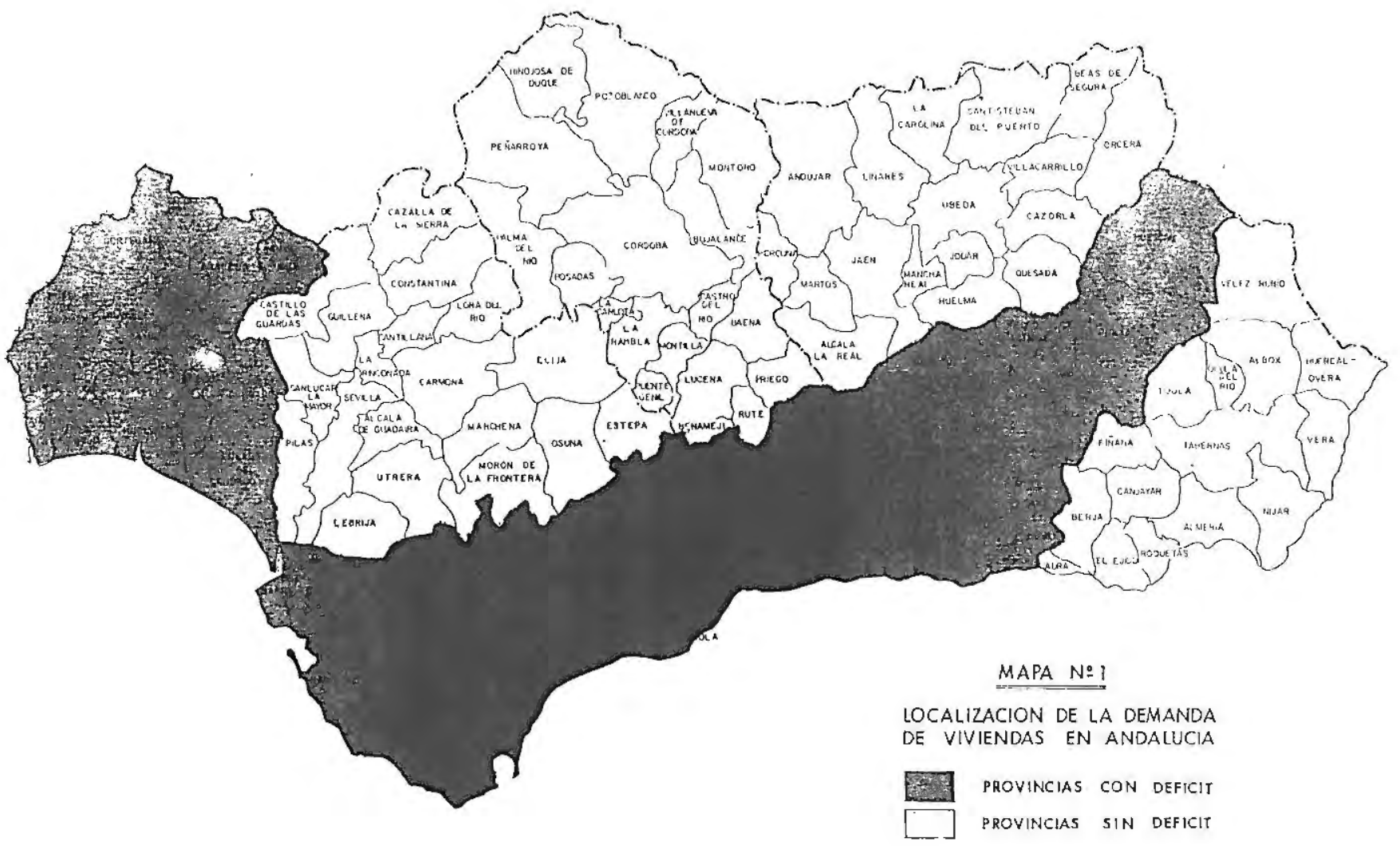




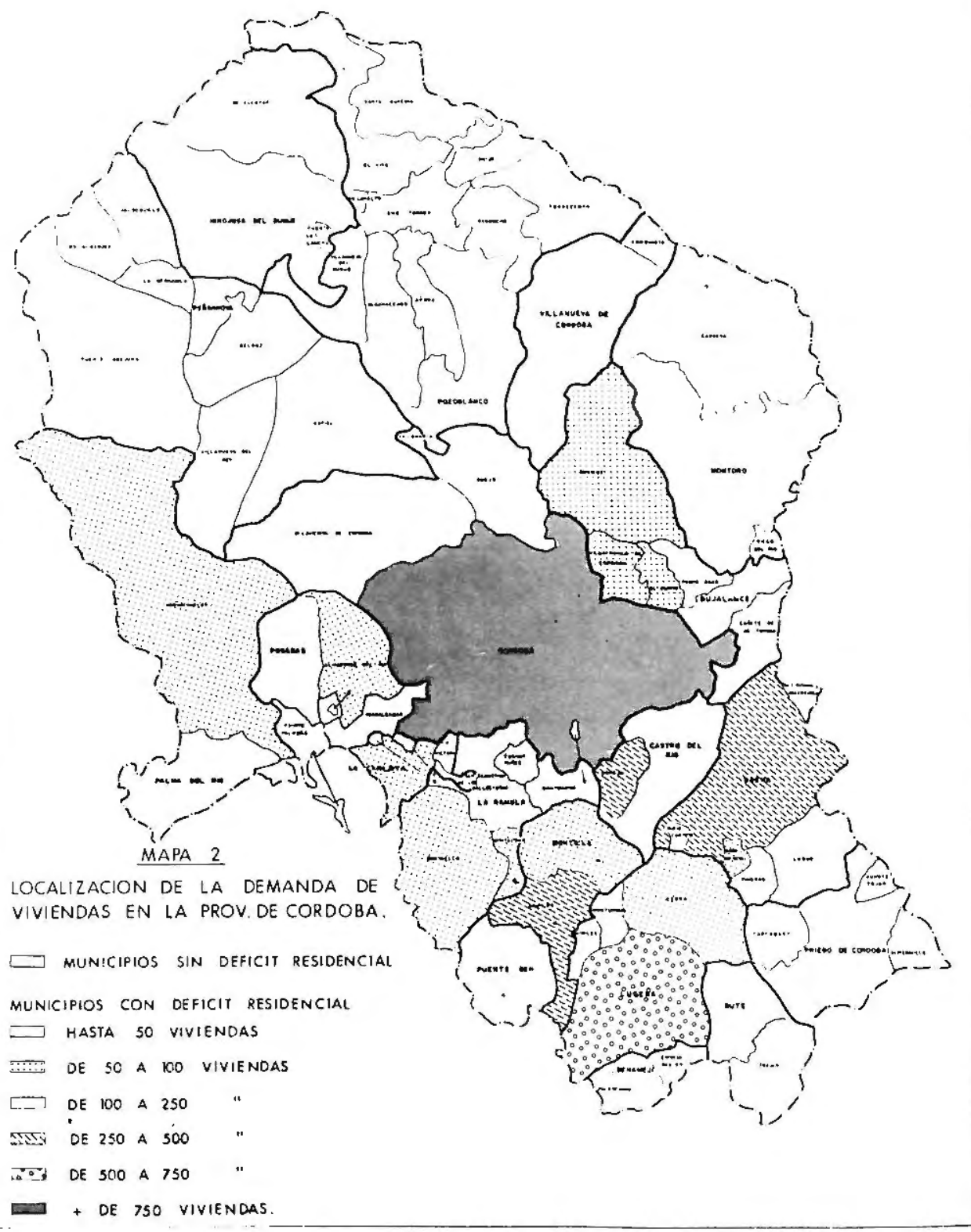




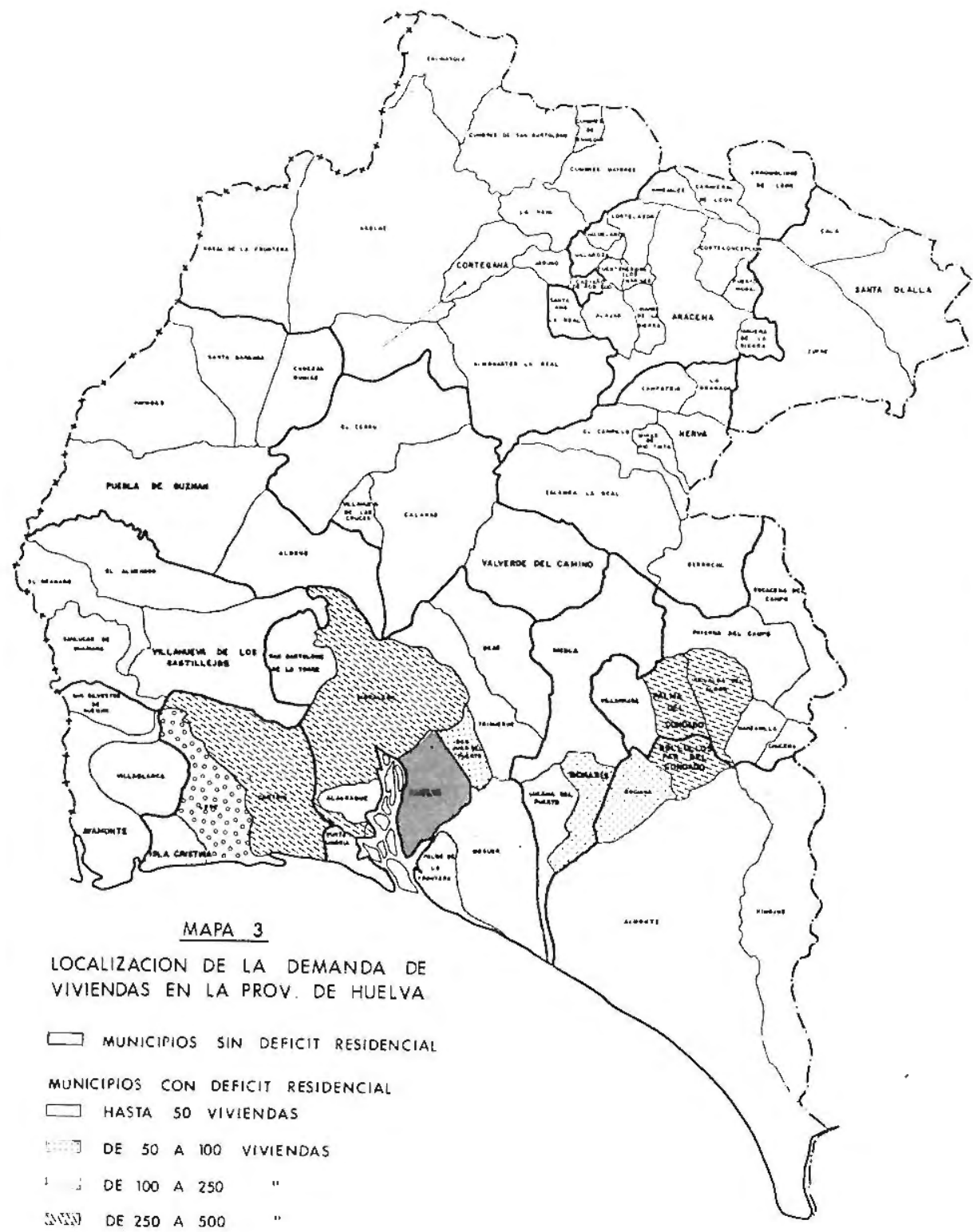

:5" DE 500 A 750 "

$\square+$ DE 750 VIVIENDAS 